\title{
Effect of processed bambara groundnuts and benne seeds on growth and organ morphology of broiler
}

\author{
AM Akanji \\ Department of Animal Production, College of Agricultural Sciences, Olabisi Onabanjo University, Yewa campus, \\ Ayetoro, Ogun State, Nigeria
}

\begin{abstract}
An experiment was conducted to determine the effects of replacing full fat soybean meal with aqueousheated, dry-heated and dehulled Bambara groundnuts (Vigna subterranea (L.) Verdc.) and benne seeds (Sesamum indicum) on performance characteristics and organ morphology of broiler chickens over a period of eight weeks. Anti-nutritional factors in the raw and processed plant seeds were determined. Higher amounts of haemagglutinin (HG) and trypsin inhibitor ( $\mathrm{TI}$ ) were found in the raw Bambara groundnuts, and tannin, phytate and oxalate in raw benne seeds respectively. Both HG and $\mathrm{TI}$ were completely destroyed in aqueous-heated Bambara groundnuts while the dry heated Bambara groundnuts contained residual amounts of the anti-nutrients. Higher amounts of the tannin, oxalate and phytate were removed in the dehulled benne seeds. Feed intake was statistically not significant in different treatment groups. Weight gain and feed conversion efficiency were more significantly $(p<0.05)$ reduced in groups fed dehulled Bambara groundnuts, aqueous-heated benne seeds and dryheated benne seeds. Significant $(p<0.05)$ reductions were also obtained in nitrogen retention of birds fed with dehulled Bambara groundnuts, aqueous-heated benne seeds and dry-heated benne seeds respectively. The organ morphology showed significant $(p<0.05)$ increases in weights of pancreas and kidney of birds fed dehulled Bambara groundnuts. The best improvements in the response indices were obtained in birds fed aqueous-heated Bambara groundnuts and dehulled benne seeds.
\end{abstract}

Key words: Bambara groundnuts, benne seeds, broilers, performance

Bangladesh Animal Husbandry Association. All rights reserved.

Bang. J. Anim. Sci. 2015. 44 (1): 26-32

\section{Introduction}

Grain legumes and oil seeds are sources of dietary protein and energy. In Sub Saharan Africa, grain legumes especially soy beans and groundnut cake have played major roles in the feeding of birds and animals. However, these two commodities, in recent times, are becoming expensive and scarce because of dwindling local production. Hence, there is need to investigate other under-utilized grain legumes and oil seeds.

Raw grain legumes and oil seeds have been reported to contain some anti-nutrients which are capable of exerting deleterious effects on body organs, and inhibiting the growth of chickens when fed in the raw form (Metayer et al. 2003). Among these under-utilized grain legumes and oil seeds are the Bambara groundnuts and benne seeds.
Bambara groundnut is a grain legume with an origin traced back to Africa. It is highly nutritious, and has been termed a complete food. Its seed consists of $49 \%-63.5 \%$ carbohydrate and $15 \%$ $25 \%$ protein (Murevanhema and Jideani 2013). Benne seeds, also known as sesame seeds (Sesamum indicum) are tiny, flat oval seeds with a nutty taste and a delicate, almost invisible crunch. The benne seeds come in a host of different colors, depending upon the variety, including white, yellow, black and red (Ensminger et al. 1983). Benne seeds are highly valued for their high content of oil, which is very resistant to rancidity. Health wise, benne seeds contain two unique substances: sesamin and sesamolin. Both of these substances belong to a group of special beneficial fibers called lignans, and have been shown to have a cholesterol-lowering effect in humans, and to prevent high blood pressure and increase vitamin E supplies in animals. Sesamin has also been found to protect the liver from 
oxidative damage (Kamal-Eldin et al. 1995; Kita et al. 1995).

Like most grain legumes, Bambara groundnuts contain toxic compounds such as heamagglutinin and trypsin inhibitor. Benne seed, on the other hand, has been reported to contain high amounts of tannin, phytate and oxalate especially in the hulls (Akanji 2002). All these toxic compounds are known to inhibit growth of chickens (Emiola et al. 2003). Many efforts have been made to improve the nutritive value of some grain legumes especially through the use of some processing methods such as ensiling with urea and/or ammonia, alcohol extraction, acid extraction and alkaline extraction, respectively (Ologhobo et al. 1993). Most of these methods were considered to be cumbersome and also expensive. Thus the need is therefore to investigate other simpler processing methods which can be easily utilized by farmers in the Sub Saharan Africa.

Hence, this study was carried out to process raw Bambara groundnuts and benne seeds by aqueous-heating, dry-heating and dehulling. The second objective was to evaluate and compare the effects of processed plant seeds on performance characteristics, nutrient utilization and organ morphology of broiler chickens.

\section{Materials and Methods}

Samples of Bambara groundnuts and benne seeds acquired from local markets in Maiduguri, North Eastern Nigeria were processed by aqueous heating and dry heating and dehulling methods. 


\section{Growth of birds fed bambara groundnuts and benne seeds}

considered to maximize the effects of any residual anti-nutrient. Minor adjustments were made in the ingredients to make the diets isonitrogenous and isocaloric. Methionine and lysine were added to each diet to ensure that the amino acids were not limiting for growth of birds.

Table1. Composition of starter diets $(\mathrm{g} / \mathrm{kg})$

\begin{tabular}{|c|c|c|c|c|c|c|c|}
\hline & Control & AHBG & DHBG & $\mathrm{HBG}$ & AHBS & DHBS & HBS \\
\hline Maize & 446.0 & 411.0 & 404.0 & 409.0 & 403.0 & 404.0 & 405.0 \\
\hline Full fat Soya & 300.0 & - & - & - & - & - & - \\
\hline BGN & - & 300.0 & 300.0 & 300.0 & - & - & - \\
\hline Benne seeds & - & - & - & - & 300.0 & 300.0 & 300.0 \\
\hline PKM & 89.0 & 84.0 & 86.0 & 88.5 & 104.0 & 99.0 & 98.0 \\
\hline Fish meal & 60.0 & 80.0 & 85.0 & 82.5 & 75.0 & 82.0 & 80.0 \\
\hline Blood meal & 40.0 & 60.0 & 60.0 & 55.0 & 55.0 & 50.0 & 52.0 \\
\hline Palm oil & 25.0 & 25.0 & 25.0 & 25.0 & 25.0 & 25.0 & 25.0 \\
\hline Bone meal & 20.0 & 20.0 & 20.0 & 20.0 & 20.0 & 20.0 & 20.0 \\
\hline Oyster shell & 5.0 & 5.0 & 5.0 & 5.0 & 5.0 & 5.0 & 5.0 \\
\hline Salt & 5.0 & 5.0 & 5.0 & 5.0 & 5.0 & 5.0 & 5.0 \\
\hline Vitamin/mineral & 5.0 & 5.0 & 5.0 & 5.0 & 5.0 & 5.0 & 5.0 \\
\hline DL-methionine & 3.0 & 3.0 & 3.0 & 3.0 & 3.0 & 3.0 & 3.0 \\
\hline Lysine & 2.0 & 2.0 & 2.0 & 2.0 & 2.0 & 2.0 & 2.0 \\
\hline \multicolumn{8}{|c|}{ Proximate composition } \\
\hline CCP (\%) & 23.1 & 22.8 & 23. 1 & 22.4 & 23.2 & 23.2 & 23.3 \\
\hline CME (MJ/kg) & 12.4 & 11.7 & 11.9 & 11.6 & 12.1 & 11.9 & 11.8 \\
\hline
\end{tabular}

AHBG, aqueous-heated Bambara groundnuts; DHBG, dry-heated Bambara groundnuts; HBG, hulled Bambara groundnuts; AHBS, aqueous-heated benne seeds; DHBS, dry-heated Benne seeds; HBS, hulled Benne seeds; BGN, Bambara groundnuts; PKM, Palm kernel meal; CCP, calculated crude protein; CME, calculated metabolizable energy

Two hundred and ten (210) day-old Anak commercial broiler chicks were randomly distributed into seven treatment groups with thirty (30) chicks per group. Each group was further sub-divided into 10 chicks per replicate. The birds were vaccinated against Newcastle disease on the $28^{\text {th }}$ day and gumboro (infectious bursal disease) on the $10^{\text {th }}$ and $35^{\text {th }}$ day respectively. Also, the birds were administered with medications against round worms and coccidiosis on the $39^{\text {th }}, 41^{\text {st }}$ and $47^{\text {th }}$ day of the experiment. Feed intake and body weights were recorded on a weekly basis. The experiment terminated at the end of eight weeks.

Faecal droppings from five birds in replicate group were collected at the eight week in a metabolic cage. The birds were allowed to adjust for a period of 2 days prior to faecal collection for 4 days. The faecal droppings collected for each replicate were weighed fresh, placed in aluminum foil, dried to constant weight at $80^{\circ} \mathrm{C}$ and analyzed for nitrogen retention.

Table2. Composition of finisher diets $(\mathrm{g} / \mathrm{kg})$

\begin{tabular}{lccccccc}
\hline & Control & AHBG & DHBG & HBG & AHBS & DHBS & HBS \\
\hline Maize & 580.0 & 535.0 & 530.0 & 530.0 & 552.0 & 552.0 & 553.0 \\
Full fat Soya & 300.0 & - & - & - & - & - & - \\
BGN & - & 300.0 & 300.0 & 300.0 & - & - & - \\
Benne seeds & - & - & - & - & 300.0 & 300.0 & 300.0 \\
PKM & 10.0 & 5.0 & 5.0 & 5.0 & 5.0 & 5.0 & 5.0 \\
Fish meal & 35.0 & 62.5 & 70.0 & 55.0 & 50.0 & 52.0 & 49.0 \\
Blood meal & 30.0 & 52.5 & 50.0 & 65.0 & 48.0 & 56.0 & 48.0 \\
Bone meal & 25.0 & 25.0 & 25.0 & 25.0 & 25.0 & 25.0 & 25.0 \\
Oyster shell & 5.0 & 5.0 & 5.0 & 5.0 & 5.0 & 5.0 & 5.0 \\
Salt & 5.0 & 5.0 & 5.0 & 5.0 & 5.0 & 5.0 & 5.0 \\
Vit./min. & 5.0 & 5.0 & 5.0 & 5.0 & 5.0 & 5.0 & 5.0 \\
DL-methionine & 3.0 & 3.0 & 3.0 & 3.0 & 3.0 & 3.0 & 3.0 \\
Lysine & 2.0 & 2.0 & 2.0 & 2.0 & 2.0 & 2.0 & 2.0 \\
Proximate composition & & & & & & \\
CCP (\%) & 20.4 & 20.1 & 20.1 & 22.2 & 20.7 & 20.9 & 20.1 \\
CME (MJ/kg) & 12.8 & 12.5 & 12.4 & 12.0 & 12.5 & 12.8 & 12.3 \\
\hline
\end{tabular}

AHBG, aqueous-heated Bambara groundnuts; DHBG, dry-heated Bambara groundnuts; HBG, hulled Bambara groundnuts; AHBS, aqueous-heated benne seeds; DHBS, dry-heated Benne seeds; HBS, hulled Benne seeds; BGN, Bambara groundnuts; PKM, Palm kernel meal; CCP, calculated crude protein; $C M E$, calculated metabolizable energy

Five birds from each replicate group were randomly selected at end of the eight week of the experiment, fasted overnight and killed by cervical dislocation. The internal organs were quickly dissected out, weighed fresh and calculated as percentage of body weight.

Statistical analysis was carried out using analysis of variance. Where significant treatment effects were obtained, their means were compared using the Duncan multiple range test (Steel and Torrie, 1980).

\section{Results}

The chemical compositions of raw, aqueousheated, dry-heated and dehulled Bambara groundnuts and benne seeds revealed slight differences in their contents of crude protein and crude fibre (Tables 3 and 4). Higher values of 
fat were however obtained in the benne seeds. Higher amounts of trypsin inhibitor and haemagglutinin activities were observed in Bambara groundnuts. The tannin, oxalate and phytate contents were however higher in the benne seeds. Aqueous heating destroyed the trypsin inhibitor and haemagglutinin contents, while dry heating and dehulling left residual amounts of anti-nutrients in the Bambara groundnuts. Higher amounts of tannin, oxalate and phytate contents were removed from the dehulled benne seeds.

Table 3. Proximate composition of raw and processed Bambara groundnut and Benne seeds

\begin{tabular}{lllllllll}
\hline & RBG & AHBG & DHBG & HBG & RBS & AHBS & DHBS & HBS \\
\hline DM (\%) & 97.7 & 94.4 & 96.8 & 95.1 & 96.6 & 94.6 & 95.4 & 95.8 \\
CP (\%) & 20.3 & 19.8 & 20.8 & 21.3 & 25.2 & 23.1 & 25.9 & 26.3 \\
CF (\%) & 3.2 & 3.1 & 3.0 & 2.6 & 4.0 & 3.6 & 3.7 & 3.1 \\
EE (\%) & 6.7 & 6.0 & 6.2 & 5.9 & 52.8 & 50.7 & 51.7 & 51.9 \\
Ash (\%) & 3.5 & 3.3 & 3.1 & 3.1 & 5.3 & 4.9 & 5.1 & 5.1 \\
NFE (\%) & 64.0 & 62.2 & 63.7 & 62.2 & 9.3 & 12.3 & 9.1 & 9.4 \\
\hline
\end{tabular}

RBG, raw Bambara groundnuts; AHBS, Aqueous-heated benne seeds; DHBS, dry-heated Benne seeds; RBS, Raw Benne seeds; AHBG , Aqueous-heated Bambara groundnuts; DHBG, Dry-heated Bambara groundnuts; HBG, Hulled Bambara groundnuts; HBS, Hulled Benne seeds; $D M$, dry matter; $C P$, crude protein; $C F$, crude fibre; $E E$, ether extract; NFE, nitrogen free extract

Table 4. Anti-nutritional factors in raw and processed Bambara groundnut and Benne seeds (\%)

\begin{tabular}{lcccll}
\hline Factors & $\begin{array}{l}\text { Haema- } \\
\text { gglutinin } \\
\text { (Hu/mg }\end{array}$ & $\begin{array}{l}\text { Trypsin } \\
\text { inhibitor } \\
\text { (Tiu/mg }\end{array}$ & $\begin{array}{l}\text { Tannin } \\
\text { (g/100gdm) }\end{array}$ & $\begin{array}{l}\text { Phytate } \\
\text { (g/100gdm) }\end{array}$ & $\begin{array}{l}\text { Oxalate } \\
\text { (g/100gdm) }\end{array}$ \\
protein) & & & \\
\hline RBG & 5.0 & 9.4 & 0.4 & 0.3 & 0.2 \\
AHBG & - & - & 0.2 & 0.2 & 0.1 \\
DHBG & - & 2.4 & 0.4 & 0.3 & 0.2 \\
HBG & 4.1 & 8.9 & 0.2 & 0.2 & 0.2 \\
RBS & - & - & 2.4 & 5.2 & 2.3 \\
AHBS & - & - & 1.7 & 3.8 & 1.6 \\
DHBS & - & - & 2.1 & 4.7 & 2.0 \\
HBS & - & - & 0.8 & 1.4 & 0.9 \\
\hline
\end{tabular}

Performance characteristics of the birds are shown in Table 5. Feed intake values were statistically insignificant in all the treatment groups. Weight gain was more significantly $(p<0.05)$ reduced in birds fed dehulled Bambara groundnuts, dry-heated Bambara groundnuts, aqueous-heated benne seeds and dry-heated benne seeds. Feed conversion efficiency (FCE) of birds fed aqueous-heated Bambara groundnuts and dehulled benne seeds were significantly $(p<0.05)$ increased. Nitrogen retention (NR) values of birds fed aqueous-heated Bambara groundnuts and dehulled benne seeds were statistically $(p>0.05) \quad$ similar to that of control group. Marked $(p<0.05)$ reductions were however obtained in NR values of birds fed with dehulled Bambara groundnuts, aqueous-heated benne seeds and dry-heated benne seeds respectively.

Table 5. Performance of exotic adult cockerels fed processed Bambara groundnuts and Benne seeds

\begin{tabular}{llllllll}
\hline & Control & AHBG & DHBG & HBG & AHBS & DHBS & HBS \\
\hline FI (g/day) & 76.7 & 76.6 & 75.9 & 74.0 & $74.8^{c}$ & 75.1 & 76.1 \\
WG (g/day) & $45.4^{\mathrm{a}}$ & $42.3^{\mathrm{b}}$ & $35.1^{\mathrm{c}}$ & $30.5^{\mathrm{d}}$ & $33.4^{\mathrm{c}}$ & $32.9^{\mathrm{c}}$ & $42.1^{\mathrm{b}}$ \\
FCR & $0.61^{\mathrm{a}}$ & $0.5^{\mathrm{b}}$ & $0.46^{\mathrm{c}}$ & $0.4^{\mathrm{d}}$ & $0.45^{\mathrm{b}}$ & $0.44^{\mathrm{c}}$ & $0.5^{\mathrm{b}}$ \\
NR (\%) & $82.4^{\mathrm{a}}$ & $81.8^{\mathrm{a}}$ & $75.1^{\mathrm{b}}$ & $67.4^{\mathrm{c}}$ & $72.1^{\mathrm{b}}$ & $70.3^{\mathrm{bc}}$ & $81.1^{\mathrm{a}}$ \\
\hline
\end{tabular}

Fl, feed intake; WG, weight gain; FCR, feed conversion ratio; NR, nitrogen retention; Means with different superscript are significantly different $(p<0.05)$

The organ morphology of the birds are shown in Table 6. There were significant $(p<0.05)$ differences in the weights of liver, pancreas and kidney among the dietary treatments. Weights of the pancreas and kidney were significantly $(p<0.05)$ increased in birds fed dehulled Bambara groundnuts. Weights of the livers were significantly $(p<0.05)$ reduced in birds fed dehulled Bambara groundnuts and dry-heated Bambara groundnuts respectively.

Table 6. Organ weight as percentage of body weight of birds fed processed Bambara groundnuts and Benne seeds

\begin{tabular}{|c|c|c|c|c|c|c|c|}
\hline & Control & AHBG & DHBG & $\mathrm{HBG}$ & AHBS & DHBS & HBS \\
\hline Liver & $3.20^{a}$ & $3.10^{b}$ & $2.93^{c}$ & $2.91^{c}$ & $3.11^{b}$ & $3.09 \mathrm{~b}$ & $3.19^{a}$ \\
\hline Pancreas & $0.34^{c}$ & $0.35^{c}$ & $0.40^{b}$ & $0.45^{a}$ & $0.32^{c}$ & $0.33^{c}$ & $0.34 c$ \\
\hline Kidney & $0.59 \mathrm{e}$ & $0.63^{c d}$ & $0.65^{b}$ & $0.68^{a}$ & $0.61^{d}$ & $0.64 c$ & $0.63^{c d}$ \\
\hline
\end{tabular}

\section{Discussion}

Proximate compositions of the Bambara groundnuts and benne seeds obtained were almost similar to those reported by Lutz and Prytulski, (2008). The higher values of haemaglutinnin found in raw Bambara 


\section{Growth of birds fed bambara groundnuts and benne seeds}

groundnuts, and the tannin,oxalate and phytate contents obtained in the raw benne seeds are close to the findings of Frederic (2004). Aqueous heating completely eliminated trypsin inhibitor (TI) and haemagglutinin activities in Bambara groundnuts but dry heating did not have a similar effect on TI activity. According to Akanji, (2002) the residual trypsin inhibitor in dry-heated Bambara groundnuts must have originated from the heat-resistant Bowman-Birk inhibitor. Dehulling, when compared to aqueous and dry heating, was more effective at removing considerable amounts of tannin, oxalate and phytate contents in the benne seeds, thus confirming that these anti-nutrients are heat stable (Apata 1990) and that bulk of these antinutrients are located in the hulls of the seeds (Masoero et al. 2005).

From the results of the feeding trial, feed intake was not significantly different in all treatment groups, although numerically birds fed with dehulled Bambara groundnuts, aqueous-heated benne seeds and dry-heated benne seeds consumed the lowest. This observation on the relatively lower feed intake could be attributed to the residual haemagglutinin and tannin content in the Bambara groundnuts and benne seeds, respectively. Russell et al. (2008) reported haemagglutinin as a glycoprotein responsible for binding the virus to cells with sialic acid on the membranes, such as cells in the upper respiratory tract or erythrocytes which can affect food intake. Ortiz et al. (1993) also reported the effects of tannin in reducing feed intake of growing chicks fed faba beans.

There was a significant inhibition in the growth of chickens fed dehulled Bambara groundnuts, aqueous-heated benne seeds and dry-heated benne seeds. The inherent trypsin inhibitor and heamagglutinin in the cotyledons of the dehulled Bambara groundnuts are attributed to the reduction in the weight gain of the birds. Ologhobo et al. (1993) had earlier reported that growth inhibitory property of trypsin inhibitor in broilers was caused by the diversion of dietary sulphur amino acids from the synthesis of body tissues to the synthesis of pancreatic enzymes which are relatively rich in these amino acids. The growth inhibition in birds fed aqueous-heated benne seeds and dry-heated benne seeds could be attributed to the effects of the high residual amounts of heat stable tannin, oxalate and phytate respectively.

The efficiency of feed utilization as revealed by FCE values, and the protein efficiency ratio (PER) were lower in chickens fed dehulled Bambara groundnuts, and aqueous-benne seeds and dryheated benne seeds respectively. Residual haemagglutinin, trypsin inhibitor and tannin have been linked to poor utilization of food in nonruminants animals (Apata 1990). Emiola et al. (2003) further reported a reduction in the efficiency of feed utilization when kidney beansbased diets containing some amounts of haemagglutinin were fed to broiler chickens. According to Akanji et al. (2007), ingested haemagglutinin could combine with the carbohydrate moiety of cells lining the intestinal wall, thereby causing malfunction and disruption in cell structure, leading to a decrease in the absorption of nutrients across the gastro intestinal wall. Furthermore, formation of complexes between the dietary protein and tannin; and between some divalent minerals and phytate in birds fed benne seed based diets in this study could have contributed to the reduced FCE and PER values. However, the improved FCE and PER in chickens fed aqueous-heated Bambara groundnuts and dry-heated Bambara groundnuts are consistent with the previous findings of Udedibie and Carlini (1998) who fed heat treated jack beans to broiler chickens.

The results of nitrogen retention (NR) revealed lower values of NR in birds fed hulled Bambara groundnuts, and aqueous-benne seeds and dryheated benne seeds respectively. These lower values were probably due to increased excretion of nitrogen by the birds fed such diets. Abnormality in intestinal absorption of amino acids has been reported to cause large excretion of nitrogen (Ologhobo et al. 1993).

The results on organ morphology showed significant reduction in the weights of liver and intestine in chickens fed on dry-heated Bambara groundnuts and dehulled Bambara groundnuts respectively. This observation agrees with the earlier findings of Ologhobo (1983) when diets 
containing residual amounts of haemagglutinin and trypsin inhibitor were fed to broiler chickens. The pancreas and kidney weights were significantly increased in birds fed dehulled Bambara groundnuts which contained bulk of the residual haemagglutinin and trypsin inhibitor activities. This is in agreement with the report of Grant et al. (1983) that trypsin inhibitor stimulates hypertrophy and hyperplasia of pancreas in rats and chicks. Apata (1990) also reported distention of capillary vessels in kidneys of chickens fed raw legumes.

\section{Conclusion}

The observation in this study showed that birds fed with aqueous-heated Bambara groundnuts and dehulled benne seeds had the best significant improvements in the response indices. The aqueous heating was more efficient at eliminating the heat labile anti-nutrients (haemagglutinin and trypsin inhibitor) in Bambara groundnuts, while dehulling removed more of the heat stable anti-nutrients (tannin, oxalate and phytate) in benne seeds. The poor performance of birds fed dehulled Bambara groundnut revealed that bulk of its anti-nutrients were located in the cotyledons of the seed. Hence, it is suggested that processing Bambara groundnuts through aqueous heating and benne seed through dehulling will go a long at enhancing their nutritive value in diets of broiler chickens.

\section{References}

AOAC (1984). Official Methods of Analysis (14 ${ }^{\text {th }}$ edn) Association of Official Analytical Chemists, Washington, DC.

Akanji AM (2002). Enhancing the utilization of some tropical legume seeds in diets of exotic meat type and egg type chickens. PhD thesis, University of Ibadan, Nigeria.

Akanji AM, Ologhobo AD, Emiola IA (2007). Utilization of some raw tropical legumes in diets of exotic adult cockerels. Journal of Animal and Veterinary Advances, 6: 485489.

Apata DF (1990). Biochemical, nutritional and toxicological assessment of some tropical legume seeds. PhD Thesis, University of Ibadan.
Ensminger $\mathrm{AH}$, Ensminger $\mathrm{ME}$, Kondale JE, Robson JRK (1983). Foods and Nutrition. Encyclopedia, Pegus press, Clovis, California.

Frederic R (2004). The Book of Edible Nuts. Dover Publications. P. 46

Grant G, Moore LJ, Mckenzie NH, Stewart JC, Pusztai A (1983). A survey of the antinutritional and haemagglutinin properties of legume seeds generally available in the UK. British J ournal of Nutrition, 50: 207-214.

Kamal-Eldin A, Pettersson D, Appelqvist LA (1995). Sesamin (a compound from sesame oil) increases tocopherol levels in rats fed ad libitum. Lipids, 30: 499-505.

Kita S, Matsumura Y, Morimoto S (1995) Antihypertensive effect of sesamin. II. Protection against two-kidney, one-clip renal hypertension and cardiovascular hypertrophy. Biological and Pharmaceutical Bulletin, 18: 1283-5. 1995.

Metayer JP, Barrier-Guillot B, Skiba F, Crepon K, Bouvarel I, Marget $P$, Duc $G$, Lessire $M$ (2003). Nutritional value of three faba bean cultivars for broiler chickens and adult cockerels. Spring Meeting of the WPSA, French Branch, P. 824-815.

Masoero F, Pulimeno AM, Rossi F (2005). Effect of extrusion, expansion and toasting on the nutritional value of peas, faba beans and lupins. Italian J ournal of Animal Science, 4: 177-189.

Murevanhema YY, Jideani VA (2013). Potential of Bambara groundnut (Vigna subterranean (L.) Verdc) milk as a probiotic beverage-a review. Critical Reviews in Food Science and Nutrition, 53: 954-67.

Ologhobo AD (1992). Nutritive values of some tropical (West African) Legumes for poultry. Journal of Applied Animal Research, 2: 93104.

Ologhobo AD, Fetuga BL (1983). Trypsin inhibitor activity in some lima beans (Phaseolus lunatus) in varieties as affected by different processing methods Nutrition Report, 26: 605-611.

Ortiz LT, Centeno C, Trevifio J (1993). Tannins in faba bean seeds: effects on the digestion of protein and amino acids in growing chicks. Animal Feed Science and Technology, 41: 271-278. 
Steel RGD, Torrie JH (1980). Principles and procedures of statistics. A biometrical approach. International students edition. Mcgrawhill, New York, P. 107-109.

Udedibie ABI, Carlini CK (1998). Questions and answers to edibility problems of the Canavalia ensiformis seeds- $A$ review. Animal Feed Science and Technology, 74: 95-106.

Valdebouze P, Bergezone E., Gaborit T. DesortLaval J (1980). Content and distribution of tryps in inhibitors and haemmaggltinins in some legume seeds. Canadian Journal of Plant Science, 60: 695-701.

Van Oort MG, Hamel RJ, Slager EA (1989).The trypsin inhibitor assay. Improvement of an existing method. Proceeding of Workshop on Anti-nutritional Factors in Legume Seeds, P. 80-86. 